\title{
FORMAÇÃO DO ALUNO LEITOR ATRAVÉS DE AÇÕES EM CLUBE DE LEITURA NUMA ESCOLA DE ENSINO MÉDIO
}

Training of the reading student through actions in a Reading Club at a High School

Formación del estudiante lector a través de acciones en un Club de Lectura en una Escuela Secundaria

\author{
Antônio Martins Andrade Silva ${ }^{1}$, Vilma Nunes da Silva Fonseca*2 \\ ${ }^{1}$ Curso de Letras, Universidade Federal do Tocantins, Araguaína, Brasil \\ ${ }^{2}$ Centro Interdisciplinar da Memória dos Estágios Supervisionados, Curso de Letras, Universidade Federal do \\ Tocantins, Araguaína, Brasil. \\ *Correspondência: Câmpus de Araguaína, Av. Paraguai com Uxiramas, S/N, Cimba, Araguaína, Tocantins, \\ Brasil.CEP: 77824-838.e-mail vilmanunes@uft.edu.br
}

Artigo recebido em 06/04/2020 aprovado em 09/04/2020 publicado em 17/04/2020.

\section{RESUMO}

Com este artigo, objetivamos discutir a importância do Clube de Leitura "Leitores sem fronteiras" como ação didático-pedagógica de fomento à leitura e à promoção do letramento literário realizada numa escola de ensino médio, situada no município de Araguaína - Tocantins. A referida instituição de ensino esteve vinculada ao Programa Residência Pedagógica (2018-2020) através do Subprojeto de Língua Portuguesa, do Curso de Letras, da Universidade Federal do Tocantins - Câmpus de Araguaína. Nesta investigação qualitativa, analisamos relatos pessoais de 3 (três) alunos e da docente coordenadora das atividades do clube mencionado. Os resultados apontaram que, após a inclusão das atividades do clube no cotidiano escolar, os discentes demonstraram maior interesse pela leitura literária, havendo facilidade na aquisição das práticas de linguagem nas aulas de Língua Portuguesa/Literatura e melhor desempenho escolar ao final do processo avaliativo. Acrescentamos ainda, o registro do afloramento de jovens escritores que passaram não somente a consumir o texto literário, mas também a produzir poesia, conto e romance.

Palavras-chave: Leitura literária; Formação do leitor; Ensino de Língua e Literatura.

\begin{abstract}
With this article, we aim to discuss the importance of the Reading Club "Leitores sem fronteiras" as a didacticpedagogical action to encourage reading and the promotion of literary literacy carried out in a high school, located in the municipality of Araguaina - Tocantins. This educational institution was linked to the Programa de Residência Pedagógica (2018-2020) through the Portuguese Language Subproject, of the Curso de Letras, at the Universidade Federal de Tocantins - Câmpus de Araguaina. In this qualitative investigation, we analyzed the personal reports of 3 (three) students and the teacher who coordinated the activities of the mentioned club. The results showed that, after the inclusion of the club's activities in the school routine, the students showed greater interest in literary reading, making it easier to acquire language practices in Portuguese / Literature classes and better school performance at the end of the evaluation process. We also add the record of the emergence of young writers who started not only consuming the literary text, but also producing poetry, short stories and novels.
\end{abstract}

Keywords: Literary reading; Reader training; Language and Literature Teaching.

\section{RESUMEN}

Con este artículo, nuestro objetivo es discutir la importancia del Club de Lectura "Leitores sem fronteiras" como una acción didáctico-pedagógica para fomentar la lectura y la promoción de la alfabetización literaria que se lleva a cabo en una escuela secundaria, ubicada en el municipio de Araguaína - Tocantins. Dicha institución educativa estuvo vinculada al Programa de Residência Pedagógica (2018-2020) a través del Subproyecto de Lengua Portuguesa, del Curso de Letras, de la Universidade Federal do Tocantins - Câmpus de Araguaína. En 
esta investigación cualitativa, analizamos los informes personales de 3 (tres) estudiantes y el maestro que coordinó las actividades del club mencionado. Los resultados mostraron que, después de la inclusión de las actividades del club en la rutina escolar, los estudiantes mostraron un mayor interés en la lectura literaria, lo que facilita la adquisición de prácticas lingüísticas en clases de portugués / literatura y un mejor rendimiento escolar al final del proceso de evaluación. También agregamos el registro de la aparición de escritores jóvenes que comenzaron no solo a consumir el texto literario, sino también a producir poesía, cuentos y novelas.

Descriptores: Lectura literaria; Entrenamiento de lectores; Enseñanza de Lengua y Literatura.

\section{INTRODUÇÃO}

Neste texto, apresentamos uma reflexão acerca do trabalho de incentivo à leitura literária, realizado numa escola de tempo integral da rede estadual de ensino, situada numa área periférica do município de Araguaína - Tocantins, através das ações do Clube de Leitura "Leitores sem fronteiras" (CLLF).

O nosso objetivo é discutir a importância do CLLF a partir da voz dos alunos e da docente coordenadora do referido clube de leitura, evidenciando o protagonismo juvenil e a emancipação pela leitura.

O nosso interesse em pesquisar, compreender e relatar as práticas de leitura evidenciadas no contexto das atividades do CLLF, surgiu a partir do nosso contato com os participantes/membros do clube mencionado, através da realização do Programa Residência Pedagógica (PRP) / Universidade Federal do Tocantins (UFT) / Câmpus de Araguaína, quando a segunda autora deste texto exercia a função de professora orientadora do Subprojeto de Língua Portuguesa e o primeiro autor era residente deste mesmo núcleo.

Observamos que a escola tinha um clube de leitura atuante que empolgava os estudantes e, principalmente, víamos o resultado do trabalho desenvolvido nas participações e no interesse pela leitura que os jovens demonstravam nas aulas de Língua Portuguesa e Literatura ministradas pelos residentes do PRP. A partir daí, passamos a frequentar os encontros do clube, a registrar e a conversar com os alunos, pois gostaríamos de saber o diferencial.

Diante do exposto, formulamos três questionamentos para nortear as nossas discussões: i) Como os jovens avaliam a importância de CLLF na escola?; ii) Como as atividades realizadas pelo CLLF afetaram o aprendizado e a formação escolar dos alunos?; iii) Como o CLLF contribuiu para a formação leitora dos estudantes participantes do projeto?

Além da introdução, considerações finais e referências, este artigo apresenta as seguintes seções: Conhecendo o contexto escolar de uma escola de tempo integral; O clube de leitura; A literatura na formação do sujeito crítico e autônomo; Sobre a realização de projetos de leitura na escola pública; Aspectos metodológicos da investigação; O CLLF e os desafios de formar leitores.

\section{CONHECENDO O CONTEXTO ESCOLAR DE UMA ESCOLA DE TEMPO INTEGRAL}

A criação de um clube de leitura, na escola investigada, compreende uma das ações do plano de atividades extracurriculares discriminado no projeto de expansão de ensino para a modalidade "tempo integral". Além do clube de leitura, a escola dispõe de um clube de ciências, um clube de xadrez e um clube de dança.

O contato com o contexto investigado se deu através da realização do PRP na escola, quando tomamos ciência do Programa Jovem em Ação (PJA), nome utilizado no Estado do Tocantins para o "Escola da Escolha", Programa do Instituto de 
Corresponsabilidade pela Educação (ICE) numa parceria com o Ministério da Educação e Cultura (MEC).

$\mathrm{Na}$ ocasião, a unidade ensino em questão vivenciava o terceiro ano de implantação do PJA, para o qual é fundamental alicerçar as diretrizes educacionais em cinco premissas: Protagonismo, Formação continuada, Excelência em Gestão, Corresponsabilidade e Replicabilidade, conforme aponta o Projeto Político Pedagógico (2019) da referida instituição escolar.

Essa escola recebe alunos de diferentes bairros que se assemelham pela flagrante concentração de problemas de ordem social e econômica. De acordo com o Projeto Político Pedagógico (2019), “grande parte dos estudantes está exposta a fatores de vulnerabilidade social, como: pobreza, prostituição, gravidez na adolescência, alcoolismo, uso e tráfico de drogas, violência urbana" (PPP, p. 8), dentre outros fatores que contribuem para desestruturação socioafetiva de adolescentes e jovens.

A ênfase do modelo de ensino adotado está centralizada no jovem e o seu projeto de vida, por isso, as práticas educativas evidenciadas na instituição focalizam o protagonismo juvenil, como resposta as demandas requeridas para uma formação cidadã.

Um dos diferenciais da "Escola Jovem em ação" é o Acolhimento que é posto aos alunos para que eles vejam e sintam em sua realidade a disposição da instituição em ajudá-los em seu "Projeto de Vida". Dessa forma, o jovem é levado a projetar o seu futuro, suas escolhas para a vida.

A preocupação com o protagonismo do aluno surge como principal pilar das ações didáticas dos professores, assim como das ações administrativas da gestão escolar. Os jovens são instigados a desenvolver habilidades que favoreçam a aquisição de conhecimentos conceituais, procedimentais e atitudinais (ZABALA, 1998) no âmbito da vivência em sala de aula, mas também para além dela.

\section{O CLUBE DE LEITURA}

O CLLF foi criado em 2017 e contava com a participação de 18 alunos ( $1^{\circ}$ aos $3^{\circ}$ anos), em 2019. Os alunos foram convidados a aderir ao grupo que se reunia na biblioteca da escola sob a coordenação da bibliotecária (docente coordenadora) que assume o papel de mediadora de leitura.

O CLLF, além de formar leitores, também tem a missão de criar iniciativas que visem a agregar os não leitores por meio da realização de subprojetos que envolvam as artes integradas (literatura, música, dança, artes plásticas).

Por esta razão, em 2019, a biblioteca e o CLLF chegaram a realizar ações, tais como:

- "Doe livros, doe conhecimento": trata-se uma atividade de mobilização da comunidade escolar para doação livros para o acervo da biblioteca;

- "Pomar literário": são destinados aos alunos livros de diferentes gêneros (ficção, poesia, romance) que tenham relação com o projeto de vida dos discentes;

- "Semana do Romance": são confeccionados cartazes, distribuídos pela escola, que abordam diferentes nuances de romances lidos pelos alunos;

- "Rodas de leitura": na roda são discutidos diferentes temas do interesse dos alunos, com base nas obras literárias estudadas no CLLF e na sala de aula;

- “Apresentações teatrais": são focalizados a leitura oral do texto literário, a encenação, a gestualidade, o trabalho com corpo e a voz;

- "Semana do Halloween": é enfatizada a literatura gótico (poesia e prosa), a arte gótica 
de modo geral (pintura, escultura, arquitetura).

\section{A LITERATURA NA FORMAÇÃO DO SUJEITO CRÍTICO E AUTÔNOMO}

A literatura é uma forma de manifestação do ser humano por meio das palavras e anda lado a lado com a música, o teatro, a dança, a escultura, a arquitetura e várias outras manifestações artísticas. Ela tem o poder de comunicar, expressar o sentir, criar no externo o que o mundo interno produz. A literatura nos fazer viajar, conhecer outros mundos, novas realidades, descortinando o que nos faz não enxergar o que somos, por isso nos ajuda a descobrir quem somos.

Segundo Lajolo (2001), hoje, temos obras literárias para todos os gostos que cada vez mais nos aproxima de realidades distintas e de representações variadas de mundos:

\begin{abstract}
A literatura fala de vários mundos: alguns parecidos com os nossos, onde, por exemplo, tem gente que morre de fome nas ruas, e de mundos muito diferentes, onde vivem espíritos, anjos, energias e demônios. (LAJOLO, 2001, p. 9)
\end{abstract}

Entendemos que a literatura não pode ser definida com um simples conceito, devido a vasta função social que desempenha na formação do indivíduo. O seu papel vai além de nos deixar informados da cultura de um povo, pois leva o ser humano a se reconhecer e a descobrir a sua identidade, por isso a literatura não consiste numa simples definição acabada em si, ela se transforma de tempos em tempos.

Segundo Cosson (2014), a literatura faz parte das comunidades humanas e se mostra importante desde antiguidade, por meio da qual tivemos acesso as histórias de como surgiu o mundo, como nasceu o primeiro homem e como ele recebeu o castigo da morte. Essas histórias construíam a nossa identidade, DOI: http://dx.doi.org/10.20873/uftsupl2020-8846 estabeleciam a ordem, as normas e davam sentido à vida.

A partir desta reflexão, vemos que a literatura também é responsável pela formação de valores e ideais do ser humano. Ao conhecer mais sobre a nossa literatura, entramos em contato conosco e, ao mesmo tempo, conhecemos áreas antes desconhecidas pelo nosso consciente. A partir do contato com os gêneros e espécies literárias, desenvolvemos a leitura e a capacidade de reconhecer elementos como: o espaço em que se vive ou que se passou em determinada obra (presente, passado ou futuro), personagens e as características das criações literárias. Também desenvolvemos as habilidades de falar e de ouvir (com atenção), além da capacidade de expor nossos pontos de vista a partir de experiências pessoais e vivências literárias.

Neste sentido, considerando o campo das singularidades e das ressignificações dos fenômenos socioculturais, a literatura supera a definição aristotélica de "arte mimética" da realidade. Por esta razão, situamos as palavras de Colomer (2003) ao redefinir a construção de sentido da obra literária:

[...] a literatura não é um reflexo mimético das condições sócio-históricas, mas exerce uma função de construção do conhecimento, de criação do mundo modelador da realidade, a qual configura e dá sentido (COLOMER, 2003, p. 93-94)

A literatura educa, transforma, modela, dá sentido e constrói o sujeito que aprende a lidar com as intempéries que a vida impõe. Transforma indivíduos em pessoas ativas, reflexivas com a capacidade de interrogar, criticar e desconstruir o que não está de acordo com o bem comum.

SOBRE A REALIZAÇÃO DE PROJETOS DE LEITURA NA ESCOLA PÚBLICA

Revista Desafios - v. 7, n. Supl. RP-UFT, 2020 
$\mathrm{O}$ desenvolvimento de projetos de leitura tem como objetivo inserir os alunos, principalmente, os menos favorecidos e em situação de vulnerabilidade socioeconômica, em práticas letradas visando a formação de cidadãos transformadores de suas próprias realidades. Acreditamos que a leitura liberta o indivíduo das amarras da ignorância e modifica vidas. $\mathrm{O}$ leitor exercita o direito ao pensamento autônomo e a livre expressão. De acordo com Sanfelici e Silva (2017):

O leitor, também como um sujeito mais amplo, deve ser formado com atenção à sua autonomia e condições apropriadas de analisar e julgar discursos, ideologias, posicionamentos, etc., de modo a ver o mundo da forma mais inteligível possível. Tal inteligibilidade e preparo para a diversidade são cruciais para que o indivíduo se integre e se entenda no mundo, e possa participar dele mais ativamente, de modo crítico, transformador e positivo. (SANFELICI; SILVA, 2017, p. 276)

Ao incentivar, orientar e mediar crianças, jovens e adultos em práticas de letramento, por meio de projetos de incentivo à leitura, assim como o CLLF, poderemos formar mais mediadores, que contribuirão como partícipes em seus ambientes sociais, influenciando outros leitores em formação que poderão vir a ser cidadãos aptos a lutar por uma sociedade mais justa, combatendo a discriminação e a desigualdade social.

Os projetos de formação de leitores, realizados na instituição de ensino investigada, sejam através de atividades isoladas (restritas ao professor e aos alunos em sala de aula) ou integradas a comunidade escolar, focalizam o desenvolvimento cognitivo e criativo dos alunos, visando a potencializar, principalmente, os aspectos relacionados à aquisição da língua (a oralidade, a leitura e a escrita), ao enriquecimento do vocabulário do discente e à sua capacidade de interpretar textos, dentro e fora da escola. Diante dos benefícios/vantagens apresentados, entendemos que:

[...] os círculos de leitura são, portanto, um meio de criar uma comunidade de leitores onde tanto o leitor quanto a leitura podem ser valorizados e onde ambos, professor e aluno, podem aprender e ajudar uns aos outros, reconhecendo a leitura como um processo ativo. (COSSON, 2014, p. 148).

Dessa forma, o CLLF, enquanto projeto de incentivo à leitura e à formação do leitor, visibiliza a valorização e os ganhos mútuos, do professor e dos alunos, que ocorre através da troca de experiências e de conhecimento. Vale salientar que a interação de alunos com outros alunos, que não raro, culmina numa aprendizagem de forma prazerosa e natural, deve ser estimulada, não somente nesse contexto específico, mas em todas as atividades escolares. Cabe ressaltar também que, na maioria das vezes, os projetos de leitura surgem da iniciativa de docentes, geralmente, preocupados com o desempenho escolar dos seus alunos. Por isso, essas atividades precisam ser apoiadas pelos gestores e pelos agentes administrativos responsáveis pela educação, para que haja um fortalecimento dessas práticas educativas.

\section{ASPECTOS METODOLÓGICOS DA INVESTIGAÇÃO}

Neste estudo de abordagem qualitativa, analisamos 3 (três) relatos pessoais escritos produzidos pelos alunos participantes do CLLF, selecionados aleatoriamente, como também o discurso da docente coordenadora do referido clube. Esses textos foram elaborados a partir da solicitação do residente do PRP-Língua Portuguesa que acompanhava as atividades realizadas pelo CLLF, na função de observador-participante.

Os informantes não são identificados, nem os alunos nem a docente, e os textos receberam os seguintes rótulos: relatos "A", "B", "C" e relato da 
docente. Solicitamos que, para a elaboração dos relatos pessoais, os participantes destacassem aspectos das suas experiências individuais no CLLF, ressaltando as "contribuições que o CLLF proporcionou ao aprendizado e se houve progresso no desenvolvimento da habilidade de leitura".

\section{O CLLF E OS DESAFIOS DE FORMAR}

\section{LEITORES}

Durante a realização do PRP-Língua Portuguesa, tivemos a oportunidade de participar das reuniões e das atividades do CLLF, durante os meses que estávamos vinculados à unidade escolar. Nesse período, podemos constatar que a forma na qual a leitura era dinamizada no CLLF apresentava um diferencial em relação ao trabalho de leitura realizado na sala de aula. Observamos que os alunos se empenhavam para conhecer mais sobre as leituras propostas pelo clube, chegavam a abdicar o tempo em casa para leitura e nos encontros debatiam as obras lidas, promovendo assim uma interação entre os colegas.

Visando refletir sobre as questões elencadas ao longo das discussões apresentadas, destacamos 3 (três) relatos pessoais produzidos por alunos participantes do CLLF, assim como da docente que, há três anos, coordena as atividades do grupo.

No relato do aluno "A", verificamos que o discente destaca o "protagonismo e a liderança" como aprendizado adquirido por meio do CLLF. Destacamos o valor semântico das formas linguísticas "grande relevância na minha vida".

Quadro 1: Relato A

O Clube Leitores sem Fronteiras, clube de leitura do Colégio Estadual $* * * *$ tem uma grande relevância na minha vida. Através dele eu tive a oportunidade de desenvolver meu protagonismo e liderança também (...). Fonte: Arquivo da pesquisa
$\mathrm{Na}$ conclusão do relato, o aluno "A" acrescenta que o "CLLF o fez melhorar como estudante e como ser humano”. Acrescenta: “(...) trouxe inspiração para sua vida no ambito artístico (...), hoje estou com uma obra quase pronta, com mais de 85 páginas escritas". Notamos que o aluno "A", teve um desenvolvimento muito positivo, pois foi estimulado a produzir literatura, adquirindo autonomia na escrita. $\mathrm{O}$ protagonismo e a liderança podem ser observados em diferentes aspectos e situações sociais que exijam autrocontrole e independência para realizar ações (a longo prazo ou não) e pensar soluções para os problemas.

\section{Quadro 2: Relato A (continuação)}

Em síntese, posso afirmar que o clube me fez melhor como estudante, como ser humano e também trouxe inspiração no âmbito artístico que pratico - a escrita - e um exemplo prático dessa influência positiva na minha vida, é que hoje estou com uma obra quase pronta, com mais de 85 páginas escritas.

Fonte: Arquivo da pesquisa

Segundo Cosson, (2014), os círculos de leituras fazem com que os alunos tenham mais envolvimento com o texto e, diante disso, promovem em si um desenvolvimento crítico, assim como o empoderamento do aluno nas escolhas das obras, e aprendizagem por meio dos debates entre os próprios alunos. Também acrescenta sobre a possibilidade de interpretação e na diversidade de compreensão do que foi lido, promovendo assim, capacidade na resolução de problemas, habilidade na tomada de decisões e, acima de tudo, a formação do leitor em todos os níveis de ensino.

O relato do aluno "B", traz 3 três prontos importantes onde ele discorre de forma coerente, primeiramente, sobre o clube de leitura, seu objetivo, funcionamento e métodos de articulação das atividades na escola. Após essa introdução, o aluno ressalta a importância do CLLF na sua vida, citando as áreas que o clube contribuiu de forma significativa. 
Para finalizar, o aluno discorre sobre a importância da leitura na vida do ser humano, trazendo à tona as habilidades apreendidas com a compreensão leitora.

Quadro 3: Relato B

O clube "Leitores sem fronteiras" foi criado com o objetivo de incentivar o hábito da leitura por toda a escola. O clube está envolvido em todas as ações da biblioteca juntamente com os professores da área de linguagem, ações como o Halloween, Semana do Romance e também o Café Literário que o clube faz. Nos reunimos as quartas para leitura livre ou debate do que lemos.

Fonte: Arquivo da pesquisa

Nesse primeiro parágrafo, o aluno "B" menciona que o objetivo do CLLF é promover o incentivo à leitura, a criação do hábito da leitura. Vimos que há um elo entre o CLLF e a biblioteca, os professores da área de linguagem e, principalmente, a gestão escolar, essa integração é salutar para o êxito das atividades planejadas. Observamos que as ações do CLLF alcançam, além dos alunos do clube, outros discentes que podem se interessar por literatura.

Nos encontros, após a leitura, haviam debates sobre as obras lidas, como forma de reflexão e construção das interpretações dos textos. Sobre essas discussões como atividades pós-leitura, Cosson (2014) afirma que

[...] ao lerem juntos, os participantes do grupo tornam explicito o caráter social da interpretação dos textos e podem se apropriar do repertório e manipular seus elementos com um grau maior de consciência, quer seja para reforçar ou para desafiar conceitos, práticas e tradições [...]. (COSSON, 2014, p. 139).

A prática de leitura, seguida de debate, proporciona aos alunos-leitores novas formas de associação de ideias e de interpretação do texto, como também o fortalecimento da relação pessoal, o entrosamento do grupo, a troca de saberes, o exercício da solidariedade e o crescimento intelectual conjunto.
No segundo recorte, destacamos dois pontos: a importância do Clube de leitura na vida do aluno "B" e a trecho no qual ele discorre sobre a importância da leitura na vida do ser humano.

Quadro 4: Relato B

Pois bem, o clube é de extrema importância, nele trabalhamos conjuntamente o hábito de ler. Ele me ajuda muito, pois melhorei na leitura, aprimorei o vocabulário, e também na escrita. São esses pontos pelo qual o clube funciona. Finalmente, a leitura é um ato de grande importância para a aprendizagem do ser humano, além de favorecer o aprendizado de conteúdos, melhora a escrita e a habilidade de interpretar.

Fonte: Arquivo da pesquisa

O aluno "B" ressalta a importância do CLLF e reconhece, a partir da própria experiência, os aspectos positivos do trabalho de incentivo à formação do hábito de leitura. Ele destaca o aprendizado adquirido ao longo da sua participação no CLLF (expansão do vocabulário, leitura e escrita). Esse discente aborda a importância da leitura na formação do indivíduo, evidenciando a necessidade de saber ler para aprender outros conteúdos.

Entendemos que a leitura não possui somente a função de transmitir a mensagem contida em uma obra literária. A leitura deve ser incentivada em todos espaços (dentro e fora da escola), pois ela promove um "desencadear" de visões que são emergidas das obras lidas.

A interpretação da obra literária pode ser diversa, às vezes, inesperada, naturalmente, pode haver divergência entre o leitor e o autor ou professor e aluno, isso porque a apreensão do texto é particular e demanda de fatores, tais como: conhecimento de mundo, experiência adquirida com leituras anteriores, saberes linguísticos e textuais subjacentes. $\mathrm{O}$ aprendizado também se dá em reconhecer a opinião diferente, ocorrendo na possibilidade de enxergar o texto por outro ângulo. 
[...] o fenômeno da leitura não deve ser concebido como simples "absorção" de uma certa mensagem, única e direta, da obra literária. Ao contrário, a leitura deve ser incentivada como um espaço ou atividade que permite o desencadear de múltiplas visões que cada obra sugere, isto é, interpretações variadas e imprevisíveis, e não fechadas ou previamente determinadas pelo professor ou mesmo autor do livro. Desse modo, acreditamos que deva ser dada ênfase às variadas interpretações pessoais dos alunos, pois cada uma dessas interpretações é resultado da percepção singular do universo representado no texto e da compreensão própria e particular do objeto artístico na situação de cada leitor. (SANFELICI; SILVA, 2017, p. 277)

Consoante aos relatos anteriores, o aluno "C" elenca as contribuições que o CLLF trouxe para a sua vida estudantil. Segue o texto:

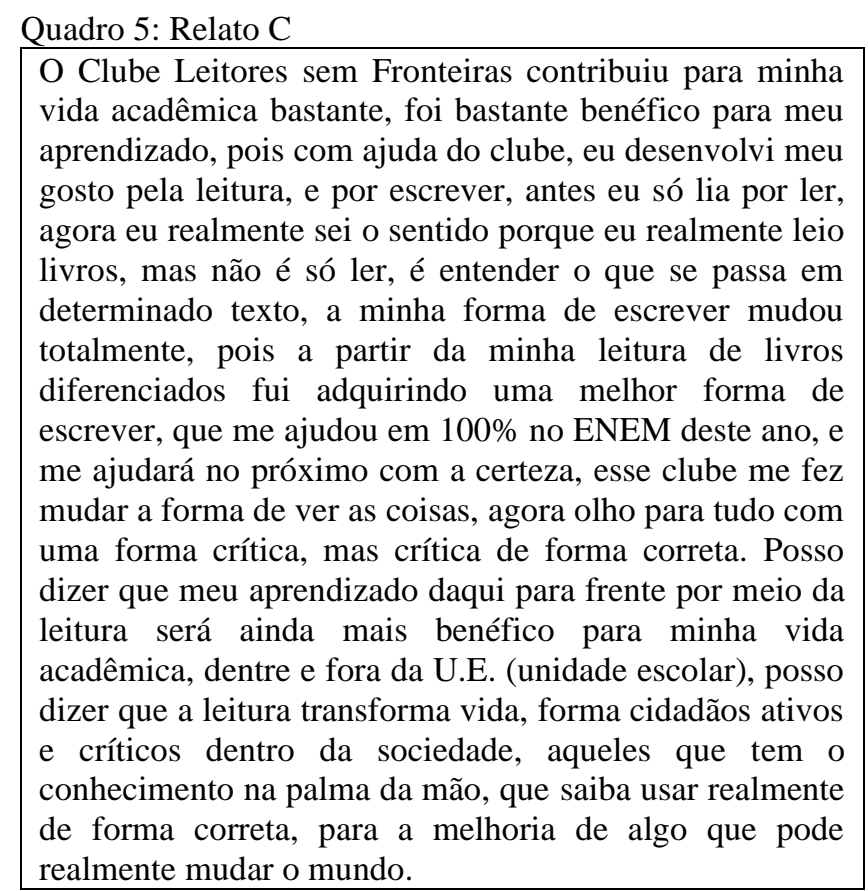
Fonte: Arquivo da pesquisa

Primeiramente, o aluno " $C$ " relata que no CLLF desenvolveu o gosto pela leitura (pois antes lia, mas não sabia da importância da leitura para sua vida e que o clube o ajudou a entender o significado do ato de ler). Acrescenta ainda que o contato com diferentes gêneros textuais lhe trouxe vantagem em avaliação nacional. Brito (2010) destaca que

A leitura é uma atividade prazerosa e poderosa, pois desenvolve uma enorme capacidade de DOI: http://dx.doi.org/10.20873/uftsupl2020-8846 criar, traz conhecimentos, promovendo uma nova visão do mundo. O leitor estabelece uma relação dinâmica entre a fantasia, encontrada nos universos dos livros $\mathrm{e}$ a realidade encontrada em seu meio social. A criatividade, a imaginação o raciocínio se sobrepõe diante deste magnífico cenário, criando um palco de possibilidades. (BRITO, 2010, p. 10).

\section{O aluno "C" registra que o ganho com a} formação do hábito de leitura não se restringe ao desenvolvimento acadêmico e reforça que a leitura transforma vidas, formar cidadãos ativos e críticos que podem mudar o mundo. Sobre esse aspecto, Brito (2010) a função da leitura está para além da interpretação de signos:

A leitura é algo muito amplo, não pode apenas ser considerada como uma interpretação dos signos do alfabeto. Produz sentido, ou seja, surge da vivência de cada um, é posta como prática na compreensão do mundo na qual o sujeito está inserido. Tal aprendizagem está ligada ao processo de formação geral de um indivíduo e sua capacitação dentro da sociedade, como por exemplo: a atuação política, econômica e cultural, o convívio com a sociedade, seja dentro da família ou no trabalho. (BRITO, 2010, p. 9).

No relato pessoal da docente coordenadora do CLLF, que é a bibliotecária da escola, ela destaca a realização desse projeto é uma forma de trabalhar o gosto pela leitura literária de forma dinâmica e que os alunos são protagonistas desse trabalho.

Quadro 6: Relato da docente coordenadora do CLLF

O Clube é uma forma dinâmica de trabalharmos o gosto pela leitura, onde nossos alunos são protagonistas desse trabalho realizado na EU, tendo como apoio permanente a bibliotecária que juntamente com eles discute ações e fazem ajustes sobre a rotina do clube; que em parceria com os professores de Língua Portuguesa promove também atividades que visam promover o acesso literário da nossa biblioteca, trabalho esse que atrai novos alunos e os motiva a tornar grandes leitores, pois, são realizadas leitura livre, roda de leitura, com ficha de leitura para o alunos ressalte os pontos principais dos livros lidos, resenha oral ou por escrito do livro lido, além de divulgação em sala de aula, propaganda do livro lido, algo que funciona como motivação e curiosidade a leitura de determinado livro; todos os componentes são envolvidos em ações que promovem a leitura como: Pomar literário, atividade realizada no pátio com 
exposição dos diversos gêneros literários em arvores, para que o aluno colha o conhecimento e viajo no mundo da leitura; Semana do romance com culminância no Dia dos Namorados, tendo diversos espaços com ornamentação temática abordando diversas forma de amar; Semana do Halloween para divulgar os livros que contemplam a temática terror e a biblioteca foi ornamentada com todos os personagens que lembram o evento (esqueleto, morcego, fantasminhas, além de maquiagem nos alunos e professores para o concurso do melhor personagem, sendo realizado em parceria com o professor de arte. Esse trabalho vem sendo realizado há três anos desde a implantação do Programa Escola Jovem em Ação Integral, mudando toda a dinâmica e rotina da biblioteca, tornando-a um ambiente vivo, atrativo, alegre e harmonioso em consonância às ações realizadas por diversas áreas de conhecimento desta EU.

Fonte: Arquivo da pesquisa

A professora menciona o apoio permanente da biblioteca, dos professores e da gestão escolar e que destaca as atividades desenvolvidas pelo clube: leitura livre, rodas de leitura, divulgação de obras nas salas de aula, pomar literário, teatro entre outras ações. Além das atividades de rotina, o CLLF propiciou a inclusão de subprojetos paralelos articulados pela docente e pelos alunos: Pomar Literário, Semana do Romance, Semana do Halloween etc.

A coordenadora do CLLF também enfatiza a preocupação com a produção escrita e ressalta que os alunos são orientados a elaborar resenhas e resumos das obras. O grupo também realiza a divulgação dos textos literários nas salas de aula com objetivo de cativar outros leitores.

Segundo a docente, o CLLF é uma ação que a escola adotou quando passou a ser uma escola de tempo integral, com a adesão do PJA. Diante das mudanças implementadas com o PJA, a biblioteca assumiu um novo modelo didático-pedagógico, vindo a se tornar um ambiente mais vivo, atrativo, alegre e agradável para os alunos, principalmente, devido a existência do CLLF.

Analisando o relato da responsável pelo CLLF, é importante refletirmos sobre o papel da biblioteca na escola e sobre como os projetos políticos pedagógicos podem orientar o corpo DOI: http://dx.doi.org/10.20873/uftsupl2020-8846 docente na realização de atividades diferenciadas nas bibliotecas escolares. Geralmente, a biblioteca é vista apenas como espaço de pesquisa, mas também pode ser um ambiente de ensino compartilhado com troca de experiências e mediação de leitura. De acordo com Jesus (2015):

[...] os projetos de incentivo à leitura, realizados nas escolas podem acontecer e garantir um bom desempenho no desenvolvimento do processo ensino/aprendizagem e na formação do leitor crítico, principalmente naquelas que possuem bibliotecas adequadas. (JESUS, 2015, p. 9)

Segundo Jesus (2015), o responsável pela biblioteca, para fazer um trabalho produtivo, precisa conhecer o contexto socioeducacional, no qual a escola está inserida. Obrigatoriamente, é necessário averiguar os interesses dos alunos, a faixa etária, os textos/gêneros literários preferidos pelos discentes etc.

Jesus (2015) sugere algumas atividades que podem ser realizadas para fortalecer os clubes de leitura que funcionam nas bibliotecas escolares, visando a formação de leitores.

Quanto às atividades desenvolvidas pela biblioteca, realizadas com as turmas dentro da grade curricular, cumpre assinalar que o responsável pela mesma deve criar meios para atrair um número cada vez maior de leitores e conservar o hábito de leitura através de clubes de leitura, criação de histórias, dramatização, varal de poesias, festivais artísticos, debates e palestras, concursos, hora do conto, janela mágica, tarde de autógrafos e outras atividades que os alunos sugerirem. (JESUS, 2015, p.13)

A partir da experiência desenvolvida no CLLF, compreendemos que a ideia de criação do clube de leitura pode ser replicada em outras instituições de ensino, tendo em vista os resultados positivos obtidos na unidade escolar investigada. De fato, constatamos que o CLLF movimenta a escola, estimula a leitura e a produção escrita de textos Revista Desafios - v. 7, n. Supl. RP-UFT, 2020 
literários e dinamiza as atividades de linguagem (dentro e fora da sala de aula), onde o aluno pratica a criticidade, a reflexão e a autonomia.

\section{CONSIDERAÇÕES FINAIS}

Esta pesquisa proporcionou que refletíssemos: i) Como os jovens avaliam a importância de CLLF na escola?; ii) Como as atividades realizadas pelo CLLF afetaram o aprendizado e a formação escolar dos alunos?; iii) Como o CLLF contribuiu para a formação leitora dos estudantes participantes do projeto? Essas inquietações foram surgindo à medida que interagíamos com os alunos e a docente coordenadora do CLLF, durante o PRP, quando tivemos contato e acesso ao grupo.

De acordo com a análise dos relatos pessoais apresentados neste texto, os alunos ressaltaram o crescente interesse pela leitura literária, a partir do incentivo recebido no CLLF, ainda destacaram a aquisição das habilidades de leitura e de escrita como fator condicionante para o bom desempenho escolar. Além disso, mencionaram também que, dada a formação leitora, alguns passaram a produzir textos literários (poesia, conto e romance).

Sabemos que não são todas as escolas que possuem uma biblioteca, algumas possuem apenas livros empoeirados em ambientes improvisados. Essa realidade não condiz com o contexto da escola de ensino médio investigada. Com isso ressaltamos que as condições físicas e estruturais não consistiram em obstáculos para execução do projeto do CLLF.

Um outro aspecto que possibilitou a existência do CLLF foi o estímulo e o apoio recebidos pela docente para coordenar as ações do referido clube de leitura. Por isso, é interessante divulgar, compartilhar os resultados obtidos com o CLLF para estimular outros profissionais de ensino, tendo em vista a necessidade de mais projetos como o CLLF.

Consideramos que para a formação de alunos leitores, precisamos de propostas didáticopedagógicas que incentivem o desenvolvimento de "clubes de leitura", "oficinas de leitura", ou seja ações que busquem a interação dos alunos e o contato com obras literárias e autores.

De acordo com Cosson (2014), os círculos de leitura fazem parte da ação de leitura em grupo, sendo um privilégio para os participantes, pois em contato com o outro, com as experiências do outro, aprendemos, ampliamos nossos horizontes, expandimos nossa interpretação, conhecemos realidades diferentes, fortalecemos nossas relações sociais e adquirimos habilidades pela troca de saberes.

\section{AGRADECIMENTO}

Agradecemos à CAPES pelo financiamento de bolsa durante a realização do Programa Residência Pedagógica - Subprojeto de Língua Portuguesa.

Todos os autores declararam não haver qualquer potencial conflito de interesses referente a este artigo. 


\section{REFERÊNCIAS}

BRITO, D. A Importância da Leitura na Formação

Social do Indivíduo. Revela. n. 8, p. 02-35, 2010.

COLOMER, T. Andar entre livros: a leitura literária na escola. Tradução de Laura Sandroni. São Paulo: Global, 2007.

COSSON, R. Letramento Literário: teoria e prática. São Paulo: Contexto, 2009.

Círculos de leitura e letramento literário. São

Paulo: Contexto, 2014.

DIAS, A. A formação do leitor literário na e pela universidade hoje: instantâneos de um subprojeto do PIBID. Contexto, n. 27, p. 06-25, 2015.

JESUS, P. O Papel da Biblioteca Escolar na Formação do leitor Crítico. Educação, Gestão e Sociedade. n. 17, p. 1-17, 2015.

LAJOLO, M. Literatura: leitores e leitura. São Paulo: Moderna, 2001.

SANFELICI, A. M.; SILVA, F. L. A formação do leitor literário na escola e a presença da indústria cultural no processo. Revista Linhas. Florianópolis, v. 18, n. 36, p. 273-284, jan./abr. 2017.

TOCANTINS. Projeto Político Pedagógico. Escola "Jovem em Ação" - CERB, 2019.

ZABALA, A. A Prática Educativa: como ensinar. Porto Alegre: Artmed, 1998. 